\title{
Discussion on the Changes and Renewal of the Earth Dwellings in Gannan *
}

\author{
Yifan Ling ${ }^{1}$, Yibing Jin ${ }^{1}$ \\ ${ }^{1}$ Xi'an University of Architecture and Technology , Xi'an, 710055, Shanxi, China
}

\begin{abstract}
In recent years, it is in a special period of agricultural transformation in China. As the living concept and the requirements for living space have been making a great shift, the traditional settlement space can no longer satisfy the modern agricultural production and living needs any more. Taking the earth dwellings in Gannan as the research object, this paper studied on changes of the traditional dwellings and the renewal methods of native earth dwellings. Based on a lot of investigation and interviews, the paper analyzed the transition of the construction material, techniques and the experiences about how to use and adapt to the nature during the traditional dwellings construction.
\end{abstract}

\section{Overview}

Gannan Tibetan Autonomous Prefecture is located in the southern part of Gansu Province, and it is located in the border of Gansu, Qinghai and Sichuan provinces. It is one of the ten Tibetan Autonomous Prefecture besides Tibet. In the past, Gannan state is the important throat passage from the Central Plains region to the Northwest China, is also the bond of the Han nationality and the Tibetan nationality, the two kinds of culture here survive together and live together in peace and harmony. ${ }^{0}$ (Figure 1)

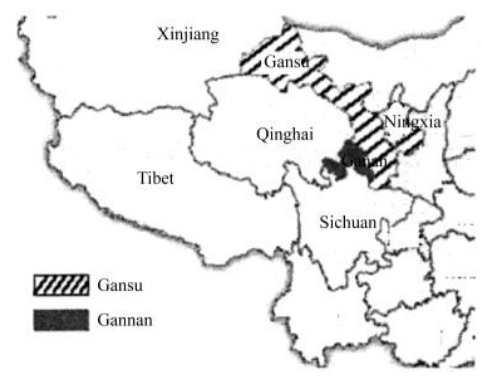

Figure1. The location of Gannan

The altitude of the whole State is above in three kilometres, and the geographical environment is complex and diverse. Geomorphic form is divided into three categories: high grassland area, which is the main pastoral areas of the whole province; high mountain forest region, which has much rainfall and the climate is mild; low hills, which is damp and cold, holding farming, forestry and animal husbandry and camp. Gannan has the characteristic of the seasonal solar term in the plateau, and the temperature of the whole state is the $1.6^{\circ}$ Celsius to $13.6^{\circ}$ Celsius. The huge area difference has formed the overall distribution trend of decreasing from Southeast to northwest. (Figure 2)

According to the special nature of the state of Gannan Tibetan Autonomous Prefecture, it is formed that there are different dwellings, such as living in the pastoral areas, the semi farmers and the people in the city. The main kind of those dwellings is the rammed earth housing for people in the semi-farming region, which is adapt to animal husbandry as the main industry, agricultural and forestry ones as the people's production and living in the auxiliary areas. ${ }^{9}$ Most dwellings building keep the Tibetan traditional architectural style, and has been influenced in different ways, by the Han nationality on the material and decoration.

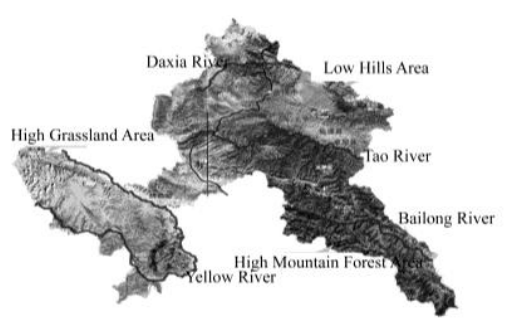

Figure2. The Terrain of Gannan

\section{The comfort of Native Earth Dwellings}

With the increase of water level and the improvement of living conditions, people are requiring much more comfortable conditions for the house. The comfort of the Gannan Tibetan traditional dwelling can be analyzed from the interior space and the structure of the building. 
Tibetan houses have a special building model, there are large standard width of the main room, small scale in depth, along with the south to a "L" - shaped or "U"shaped, for lighting which can easily go into the room. ${ }^{3}$

From the structure of the building, there are some strategies to make the room comfortable. First of all, the main construction of the dwellings is rammed earth wall, wood frame and the red earth roof, which are good in insulation performance and the environmental protection. The traditional dwellings are the ones that the construction of the inner frame and the outer part of the construction are totally separated, which is called "there is no earth inner, as well as no wood outside ".Under the alpine climate environment, it can keep warm indoor in winter and cool in summer, enhancing living comfort, and natural flexibility of wood contributes for the construction safety security.

\section{The Changes of Traditional Dwellings}

During the hundreds of years in history, the earth dwellings have been changing gradually. There are three obvious parts about the changes of traditional earth dwellings : plan, external factors and material structure.

\subsection{Plane form changes}

The traditional houses in the courtyard plane form three sides of the main points which was named "concave" shape, both sides of the "L" type and" U "shaped spatial form. Among them, Liu ancestral home ${ }^{4}$ (Liu Fuyuan's home) is more special (Figure3, Figure4), which draws on the Gannan area houses with the agro-pastoral Tibetan "cut wood capsule" form, and double doors into the front yard covered four houses, Usually people do not live through the side of the road and arrived in houses dimly lit corner called "Ma Xiang" attaching the living room. ${ }^{5}$

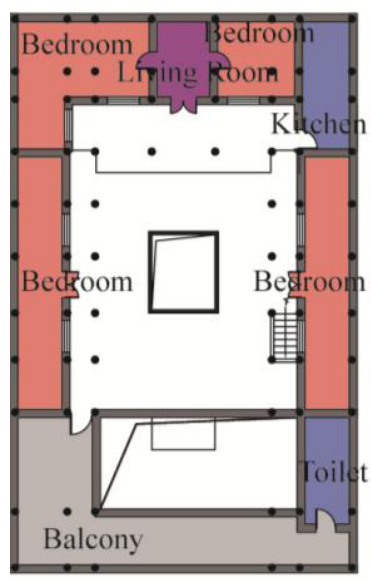

Figure3. Liu Fuyuan's home home first plan

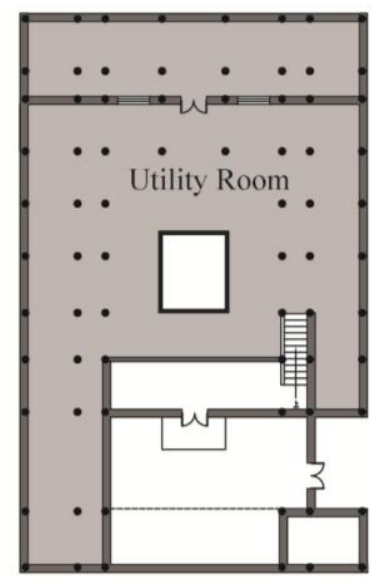

Figure4. Liu Fuyuan's second plan

\subsection{External factors affecting the changes of earth dwelling}

First, the rural industrial structure and the residents' production and life changes, and residential villages are constantly changing. Ming Dynasty village in Gannan land reclamation, historical period military recruit Defences of houses mostly similar form "Zhuang broad" external cohesion proper, a good defensive, and even into a piece of flat roofs, should be dry crops. ${ }^{6}$ Today's main industries are farming and village industries, mainly in the cultivation of barley and bupleurums based. Dwelling in cattle shed was basically abandoned, now doing some debris from time to time is idle.

Secondly, the introduction of modern construction techniques and materials is also a factor changes residential development. ${ }^{7}$ Flowing along the various mountain village a lot of red clay, the clay soil properties suitable for the local brickyard 2-3 seat, local materials to produce large amounts of clay. Mass production and application of clay also contributed to the abovementioned developments, so there become brick walls. Bright windows and light wooden windows replaced the shortcomings of bulky and easy to corrupt, wooden windows replace the results but also the development of the birth of modern glass technology. What's more, the government intervention in residential architecture changed. Such factors have led to major changes reflected in the residential appearance. Lintan which is located in the ancient Tao state, with the characteristics of immigrants, ${ }^{2}$ Flat houses has already been the "plus top" ${ }^{1}$ engineering, which uses a glass or new colour steel which is made in the original flat roof to highlight the region's legacy features, with the government's highlight in subsidy legacy. However, fortunately, today, the most villages in Gannan still retain the authentic local specialties.

\subsection{The changes of material structure}

Firstly, the main building has civil engineering structures, with the pine wood and rammed earth wall. The roof is typical of traditional houses. In the past, there was rammed earth floor in bedroom, but nowadays more and more people choose to use concrete tiling, also referring to set up a floor board approach, that can keep moisture from the floor, together with avoiding the snakes. Though the main room was rammed ground, positive set shrine, there are worship ancestral tablets, the others pick up and worship, weddings and other important ritual places.

In the research, it is found that the main room of Gannan rammed earth floor houses are changing gradually, such as hardened cement, ceramic tile veneer, or play light keel wooden floor. ${ }^{5}$ Changes in the main room floor is a certain extent reflect of the conversion of living space, the conditional resident household appliances furnishing main room are TV, fridge, etc. From the ritual space, villagers pay more attention to cleanliness and comfortable living, but also to show "secularization" tendency village life (Figure5, Figure6). Secondly, the introduction of new materials bring traditional dwellings more significant impact mainly clay the use of cement, and glass windows. ${ }^{8}$ A local survey, 
from the beginning of 2000 the increasing popularity of the red clay of the application. Besides, there are some houses with brick built into the outer profile of the rammed earth wall, which are on behalf of the original out wall, which eliminates the need for back post, saving some wood. Moreover, some local residential building using brick, with rough statistics, about $40 \%$ in such cases. Substantially all households changed the traditional wooden panes of glass windows, including more and more families also installed have sunshine room (Figure6).

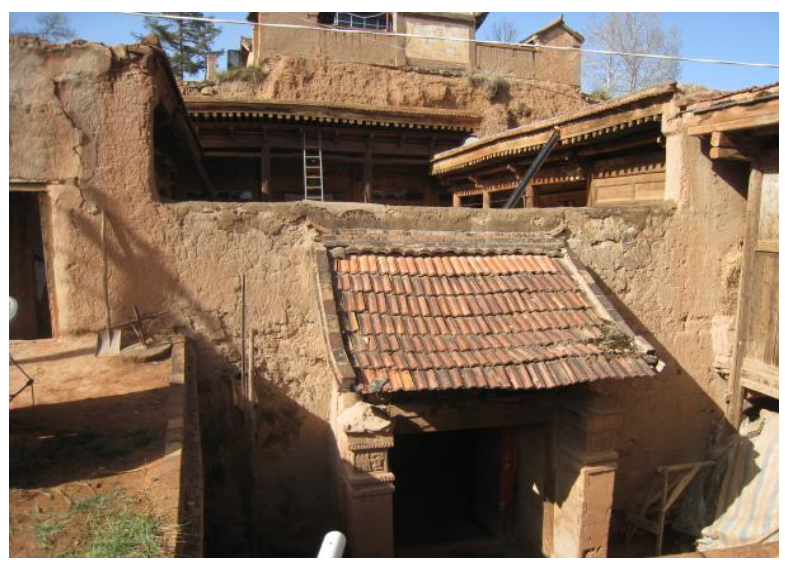

Figure5. Rammed earth wall

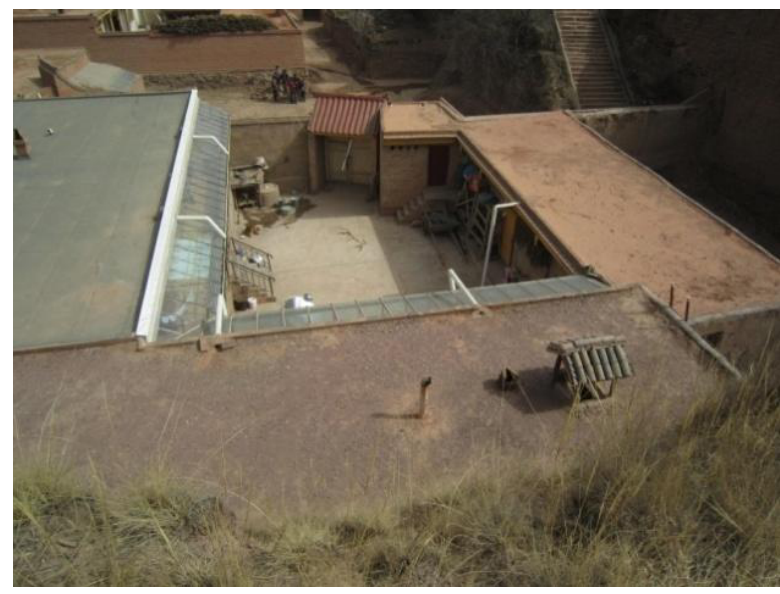

Figure6.Sunshine room

\section{Renewal of the Earth Dwellings}

Through the changing of the earth dwellings, the renewal of the earth dwellings is necessary for local people.

How to renew the traditional earth dwellings? There are two aspects to do it: function and the technical methods to make it comfort.

First, more functions are asked by local people today. More room for living is required, especially for the people who own a villa to earn money. The clean toilet inside is also required, and this kind of toilet will replace the old type. Sunshine room has become the favourite space in the whole dwellings, because it is much warmer than other place, and it can warm the inner space, such as the bedroom, living room, etc. According to the tradition, the middle part of the earth dwelling is the scary space which is used for ancestor worship. (Figure7, Figure8)

Secondly, through some technical methods to make it comfort, like some solar energy technology, subterranean heat system, the trombe wall and so on. These technologies are used for enhancing heat preservation performance of the earth dwellings.(Figure9)

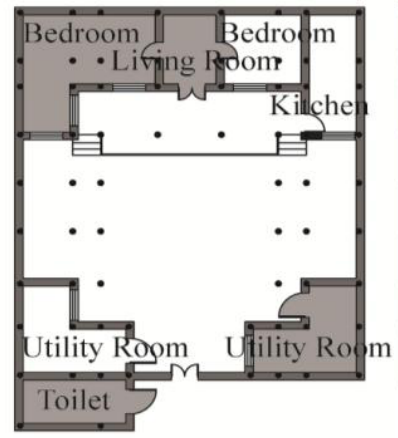

Figure7. original plan

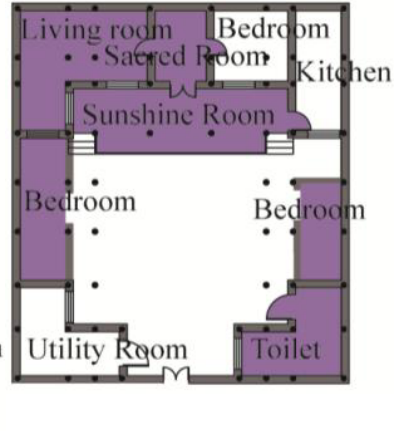

Figure8. renewal plan

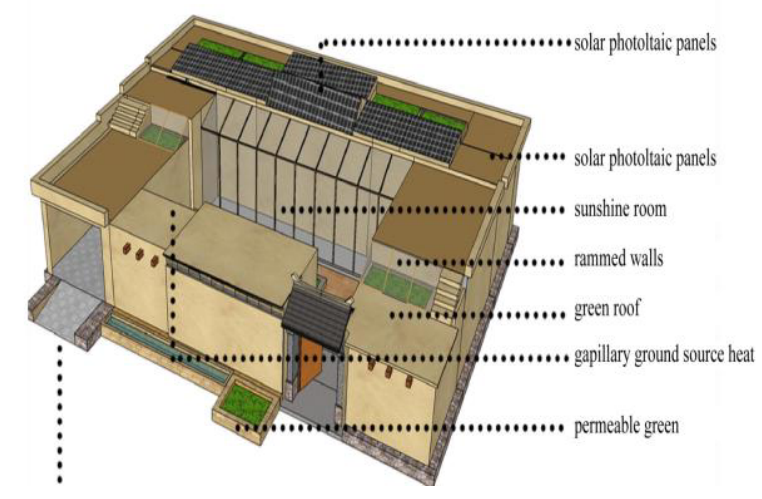

Figure9. Renewal dwellings which used some techniques

\section{Conclusion}

After a century of development, the traditional earth dwellings has changed a lot. The structure of the dwellings changed from earth to brick, however the heat preservation performance didn't promote, the original material is still the best choice for comfortable inner environment of the dwellings. However, due to the lack of clear protection strategies and development measures, today's Gannan gradual emergence of the traditional function and techniques of the old dwellings cannot meet the new requirements; the architectural style of forced change; the internal structure of the building does not meet the functional needs.

Therefore, exploring the changes of local earth dwellings, analyzing the impact of the reason why houses are changing more feasible ,and exploring the renewal activation strategy are necessary for the developing of the earth dwelling.

* "National Natural Science Foundation of China Youth Fund 51208419" 


\section{References}

1. The Compilation Committee of local chronicles of Gannan Tibetan Autonomous Prefecture, Gannan Journal,300,389,(1999)

2. Lintan County Local Records editorial board, Lintan local history Editorial, 23-35,90-99(1997)

3. Jian Liu, Yunfeng Lee, Gannan Tibetan vernacular architecture and its characteristics, Gansu Journal of Higher Normal University,12,(2007)

4. Xiaohong Zheng, The ancient Tao State: Falling beyond the Great Wall, World Vision.11 ,49(2007)

5. Yiqing Wang, Gannan Min Habitat, Northwest University for Nationalities, Philosophy and Social Sciences, 2(1992)

6. Degang Duan, Xiang Cui, Jin Wang, Gannan Zhuoni Tibetan Settlement Space Investigation, Architecture and Culture: native to create, 122( 2014)

7. Yuanding Lu, Chinese Residential Building. Guangzhou: South China University of Technology, 2003

8. Quan He, The Research on the Culture of Tibetan People in Residential Buildings, Xi'an University Of Architecture And Technology( 2009)

9. Zhiyuan Ren, , Architecture Journal,7(1983) 